\title{
Por que é necessário começar a atividade de estudo pela via do pensamento teórico?
}

\author{
Why is it necessary to start learning activity through \\ theoretical thinking?
}

Armando Marino Filho ${ }^{1}$

\section{RESUMO}

Este artigo realiza uma discussão sobre a importância de iniciar-se a atividade de estudo como atividade do pensamento teórico. O seu objetivo é demonstrar o valor do pensamento teórico para o desenvolvimento da personalidade do estudante. Para isso, propõe que, ao compreender-se esse valor como necessidade do desenvolvimento, compreendem-se, da mesma forma, os limites do pensamento empírico e as consequências da atividade de estudo para os estudantes e, também, a importante possibilidade de desenvolvimento ilimitado para a personalidade humana, quando o ensino assume como objeto o desenvolvimento do pensamento teórico. A análise focada no pensamento teórico e na personalidade fundamenta-se na Teoria Histórico-Cultural e nos autores que nela se referenciam para compreender o desenvolvimento humano, principalmente em V. V. Davidov, D. B. Elkonin, V. V. Repkin, L. S. Vigotski e A. N. Leontiev. Para tanto, analisa a origem do pensamento como contradição em relação com a percepção sensível, a sua unidade e superação pela necessidade de pensar que emerge da insuficiência da percepção para a necessidades cognitivas do ser social, isto é, o pensamento como necessidade gestada em relações sociais. Considera, finalmente, como o pensar teoricamente vem a ser ao mesmo tempo o processo e o produto necessário à atividade de estudo, e esta como atividade vital dos indivíduos, posto que o pensamento

ABSTRACT

This article discusses the importance of starting learning activity as an activity of theoretical thinking. It aims to show the value of theoretical thinking for the student's personality. For this, it proposes that, when understanding this value as a development need, the limits of empirical thinking and the consequences of students' learning activity are also understood and, also, the critical possibility of unlimited development for the human personality if teaching activity takes as its goal the development of theoretical thinking. The analysis focused on theoretical thinking and personality is based on Cultural-Historic Theory and authors who based their ideas on it to understand human development, mainly in V. V. Davidov, D. B. Elkonin, V. V. Repkin, L. S. Vygotsky and A. N. Leontiev. For this purpose, it analyzes thought origin as a contradiction in relation to sensitive perception, its unity and overcoming by the need to think that emerges from the insufficiency of perception for the cognitive demands of the social being, that is, thinking as a need generated in social relationships. Finally, it considers how theoretical thinking becomes both the process and the product necessary for learning activity and this one as a vital activity of individuals, since theoretical thinking, in our analysis, reaches the status of revolutionary social practice for personality and society.
\end{abstract}

${ }_{1}^{1}$ Psicólogo, Professor adjunto na UFMS-Cptl - Pedagogia e Licenciaturas, professor PPGE UFMS- Cptl. Trabalho resultante de pesquisas realizadas no Grupo de Pesquisa UFMS/CNPQ A Teoria Histórico-Cultural para o Ensino e Aprendizagem. ORCID: https://orcid.org/0000-00025212-3972. E-mail: armandomarinof4@gmail.com. 
teórico, em nossa análise, alcança o status de prática social revolucionária para a personalidade e para a sociedade.

Palavras-chave: Atividade de estudo. Pensamento teórico. Personalidade.
Keywords: Learning activity. Theoretical thinking. Personality.

\section{Introdução}

Muito além da aquisição de conhecimentos, a atividade de estudo cumpre um fundamental papel no desenvolvimento integral dos estudantes. Com isso queremos afirmar que todo estudante é uma totalidade viva que não pode ser decomposto e isolado, por exemplo, como um ser apenas cognitivo, durante essa atividade. Ressaltamos isso, em decorrência do fato de que, nas nossas escolas, parece haver essa ênfase na aquisição de conhecimentos como a essencialidade da atividade escolar.

A redução dos estudantes a seres cognitivos, cuja personalidade pode atrapalhar a aula do professor, exames e avaliações reduzidos à verificação da assimilação dos conhecimentos e a participação do estudante como ouvinte obediente e autocontrolado, como reprodutor dos conteúdos dados ou transmitidos na sua forma acabada não são fatores apenas contraditórios aos propósitos da educação e da formação que os estudantes poderiam ter em seu benefício. Essa forma dada à atividade de escolarização da formação cultural dos estudantes é conflitiva, prejudicial e negativa para o seu desenvolvimento.

A importância da compreensão do que vem a ser a organização de uma atividade orientada a promover o desenvolvimento psicológico, como é a atividade de estudo, está no fato de que é justamente a atividade que os sujeitos realizam que será apropriada, transformada, na sua forma e no seu conteúdo, subjetivada em suas qualidades e expressa na forma de ação orientada. Nela, os indivíduos existem integralmente, isto é, são sempre uma totalidade. Por isso, é preciso compreender o estudar como unidade afetivo/emocional-cognitiva da relação viva com o mundo socioculturalmente constituído.

Somente compreendendo que o indivíduo se forma inteiramente na atividade que realiza poderemos reconhecer o valor do desenvolvimento como objetivo da atividade de estudo. Esta não é mais uma entre outras tantas que o 
homem pode realizar; a sua especificidade centrada no pensamento teórico a coloca no topo da hierarquia das atividades que as crianças o quanto antes precisam desenvolver para a sua formação humana. De acordo com Davidov (1988, p. 12), “[...] O desenvolvimento psíquico do homem é antes de tudo o processo de formação de sua atividade, de sua consciência e, claro, de todos os processos psíquicos (processos cognoscitivos, emocionais, etc.) [...].”

Aqui, é essencial compreender a centralidade tanto da expressão socioculturalmente constituído como da relação viva. Essas duas características da atividade humana definem o desenvolvimento do pensamento e de todos os processos nele envolvidos, vale dizer, do sistema psicológico na sua integralidade, isto é, de tudo aquilo que na história sociocultural já se desenvolveu, e que na história individual dos sujeitos se tornará função psicológica. Com isso queremos afirmar que a sociedade e a cultura se constituem como atividade vital, que é, portanto, a "fonte do desenvolvimento" necessário aos sujeitos sociais.

Compreendido aqui, como afirma Leontiev (1978), que em sociedade o homem precisa aprender a ser homem, e que o que a natureza lhe deu é insuficiente para a sua realização como ser social, a atividade de estudo toma para si uma das mais importantes realizações dessa transformação. Para além da necessidade cognitiva, ela propõe, então, o desenvolvimento da personalidade humana como escopo que supera o caráter exclusivamente cognitivo da atividade escolar e coloca o próprio homem como fim. Ao fazer isso, coloca a própria sociedade como condição, meio e produto da sua atividade. É assim, porque a transformação dos indivíduos pressupõe a transformação da sociedade e viceversa, no processo contínuo e revolucionário de realização da vida humana.

O que veremos a seguir, então, é uma análise dos processos que envolvem a necessidade desta atividade, algumas das suas características essenciais e o valor que isso representa para os estudantes como pessoas e para a sociedade como seu meio de vida. Serão analisados, para tanto, o desenvolvimento humano e os processos de pensamento, o valor da autonomia e do pensamento teórico para a personalidade dos estudantes. 


\section{0 desenvolvimento humano como atividade vital e sua relação com a atividade de estudo}

Quero partir da afirmação decisiva feita por Marx (2004, p. 84) para entendermos o centro em torno do qual ocorre o desenvolvimento humano, e com o qual quero relacionar a atividade de estudo e sua importância para os indivíduos:

O homem faz da sua atividade vital mesma um objeto da sua vontade e da sua consciência. Ele tem atividade vital consciente. Esta não é uma determinidade (Bestimmtheit) com a qual ele coincide imediatamente. A atividade vital consciente distingue o homem imediatamente da atividade vital animal. Justamente, [e] só por isso, ele é um ser genérico. Ou ele somente é um ser consciente, isto é, a sua própria vida lhe é objeto, precisamente porque é um ser genérico. Eis porque a sua atividade é atividade livre.

A atividade vital, comum a todos os animais, tem como essencialidade a reprodução e manutenção da vida, a luta diária para a nutrição, proteção e garantia da continuidade da espécie. A força que impulsiona para isso não é conhecida por nós, não podemos afirmar sua gênese com base em um sentido concreto. Pelo contrário, a atividade vital humana fundada pelo trabalho, isto é, pela transformação da natureza em meios de produção da vida sociocultural, pode adquirir muitos sentidos porque é consciente. O próprio sentido humano da atividade se torna, nesse caso, vital. Isto é, um componente necessário da atividade vital social e, também, por isso mesmo, da individual.

Fazer da própria atividade, constituída de sentidos humanizados, um objeto da própria vontade implica que a consciência como a minha relação com o mundo (Marx, 2004) - possa integralizar em um mesmo sistema de relações os sentidos sociais e os pessoais. Isso quer dizer que, nas atividades que o sujeito assim realiza, ele satisfaz ao mesmo tempo as necessidades da sociedade e as suas próprias. É assim que podemos compreender cada indivíduo como totalidade. Como totalidade que se enriquece a cada momento do seu desenvolvimento, da sua humanização.

Considerando a vontade, que não preexiste nos indivíduos, mas tem sua gênese na própria atividade social, podemos compreender, de acordo com Vygotski (1997, p. 78), que “[...] qualquer processo volitivo é inicialmente social, 
coletivo, interpsicológico". E explica: "Isto relaciona-se com o fato de que a criança domina a atenção de outros ou, pelo contrário, começa a utilizar consigo mesmo os meios e formas de comportamento que ao princípio eram coletivos" (grifo nosso). Essa qualidade da vontade aponta para uma questão fundamental, a saber, a de que, de fato, na atividade, a vontade pode ou não se formar na relação do sujeito com o objeto da sua atividade. O processo de ensino pode não levar à aprendizagem dos meios e formas de comportamento para um dado processo da realidade como expressão da vontade do sujeito. Assim, o ensino pode produzir sujeitos sujeitados na atividade, sem autonomia, sem consciência de si, alienados.

Nesse caso, temos, então, duas situações: em primeiro lugar, no caso do domínio dos meios e formas do comportamento, o sujeito realiza a sua vontade por meio da atividade e, em segundo, o sujeito realiza uma dada atividade que não é a expressão da sua vontade. No primeiro caso, o indivíduo sujeita-se a si mesmo pelo seu pensamento, escolhe os modos de agir, de pensar e de objetivar-se que estão desde o início sujeitados à sua vontade, a uma tarefa que ele quer realizar. A vontade, nesse caso, pode ser traduzida como autonomia. No segundo caso, o indivíduo está sujeitado às condições, modos de agir, de pensar e de objetivar-se que estão determinados por alguma força heterógena, e, nesse caso, a vontade é alienada do sujeito.

No primeiro caso, podemos colocar um termo de igualdade entre a autonomia e "atividade vital consciente"? Como foi afirmado logo acima por Marx (2004, p. 84), "A atividade vital consciente distingue o homem imediatamente da atividade vital animal". Mas, que homem? Partindo da animalidade humana, da sua condição inicial de orientação no meio com base na sensibilidade, nos modos de agir no mundo com aquilo que lhe é próprio do tipo biológico, da espécie, podemos afirmar que nela existe também uma atividade vital que, sendo a sua condição natural, dada pelos processos de evolução da espécie, é uma atividade vital não consciente, que determina em grande medida as possibilidades de agir no meio circundante.

Quero notar que essa ação não é consciente, não há aí um indivíduo que faz escolhas conscientes pelo processo de pensamento. Não há aí sujeito autônomo. A atividade vital é, nos primeiros momentos da vida de qualquer 
indivíduo, um conjunto de ações dadas pela própria natureza do sistema orgânico como meio de se deslocar no espaço e no tempo. É necessário superar essa condição para objetivar-se como ser social.

O que virá a ser a consciência para esse homem cuja atividade vital se constitui como uma singular ação natural na sua relação com o meio? Pelo menos três condições são necessárias ao surgimento da atividade vital consciente: (1) a atividade social - homens entre si - de transformação da natureza; (2) decorrente desta, a necessidade de comunicação - intercâmbio -, que engendra (3) a transformação dos sinais da natureza em sinais artificiais (VIGOTSKI, 2001), em signos que constituem um meio especial de comunicação, a linguagem. Novamente Marx (2007, p. 34-35) sustenta, de forma decisiva, a expressão dessas três condições do surgimento da consciência, quando afirma que,

A linguagem é tão antiga quanto a consciência - a linguagem é a consciência real, prática, que existe para os outros homens e que, portanto, também existe para mim mesmo; e a linguagem nasce, tal como a consciência, do carecimento, da necessidade de intercâmbio com outros homens. Desde o início, portanto, a consciência já é um produto social e continuará sendo enquanto existirem homens.

Disso decorre que a unidade da atividade prática transformadora, da comunicação e uso da linguagem com base nos signos dá ao homem os meios para superar a limitação posta pela natureza da ação que se constitui pelo próprio movimento do corpo. Agora, de posse dos meios e instrumentos da atividade social, prática, transformadora, com base na significação, o homem alcança o status de dominar as próprias ações e organizá-las segundo a objetividade da sua atividade produtiva, a partir de uma transformada subjetividade que supera a percepção imediata da realidade, que é reproduzida em si mesma na forma de pensamento. Por isso, afirmou Leontiev (1978, p. 32-33, grifo nosso):

Como função do cérebro humano, o pensamento é um processo natural, mas não existe à margem da sociedade, à margem dos conhecimentos acumulados pela humanidade e dos procedimentos da atividade pensante elaborados por ela. Deste modo, cada homem se converte em sujeito do pensamento somente quando domina a linguagem, os conceitos e a lógica, que constituem um reflexo generalizado da experiência da prática social: inclusive aquelas tarefas que o homem 
propõe ao seu pensamento são um produto das condições sociais de sua vida. Em outras palavras, o pensamento dos homens, assim como sua percepção, são de natureza histórico-social.

A consciência dos indivíduos sujeitados às condições da vida social virá a ser para eles a sua própria ação caracterizada pela atividade social e não mais pelas características da atividade motora natural. Quer dizer isso que o indivíduo toma a consciência da sua relação com a realidade da atividade social. Constituise doravante como indivíduo social, sujeito e sujeitado pelas relações de poder e domínio da sua própria atividade, como ser autônomo, que faz escolhas relacionadas a objetivos também conscientes. A objetividade da sua atividade expressa a consciência no e para o mundo no qual existe. A atividade social agora é a sua atividade vital. Ou seja, a sua atividade vital individual é social.

Compreendemos, assim, que a importância da organização da atividade dos sujeitos com vistas ao seu desenvolvimento psicológico, está relacionada à qualidade da consciência que se formará como produto das suas ações. $\mathrm{Na}$ atividade social, como sujeito das ações que realiza coletiva ou individualmente, a consciência se forma com diferentes qualidades, valores afetivo-emocionais e cognitivos. Na sua totalidade, o sistema psicológico e a personalidade precisam ser tomados como parâmetro da análise do desenvolvimento, mais do que a aquisição de conhecimentos, ou qualquer outra característica específica.

A conquista da autonomia, por isso, tem um valor para a personalidade. Representa a possibilidade de autorrealização nas atividades sociais, do reconhecimento do produto da sua atividade como expressão da sua vontade. Por isso, a autonomia adquire um valor vital para a realização individual da vida social dos sujeitos, porque não só é meio de garantir a existência na forma do ser social da cultura na qual existe, mas, e mais importante ainda, possibilita para os indivíduos a criação de novas realidades tanto para si como para a sua comunidade. Nas palavras de Marx (2004, p.84), a qualidade essencial da consciência, a meu ver, é que “[...] a sua atividade é atividade livre”.

Mas isso pode não se realizar plenamente nos indivíduos que, mesmo vivendo em sociedade, permanecem naquela qualidade de ser alienado da sua 
vontade. Esse homem não se realiza como aquele que Marx apontou como sendo alguém que se distingue da atividade vital animal porque sua atividade consciente é vital. Nele, a atividade é dominada por forças estranhas ao seu possível ser humano consciente. Ele está condenado a realizar somente as necessidades mais simples de manutenção da sua vida, pelo trabalho não criativo, não transformador da realidade nem da sua nem da sociedade na qual vive. A sua atividade por muito pouco se diferencia daquela atividade vital animal.

A relação, portanto, que se pode estabelecer da atividade humana social consciente com a atividade de estudo é que, se nesta se cumpre o objetivo da transformação pessoal no sentido da atividade consciente, ela cumpre seu papel na humanização dos sujeitos. Essa transformação está diretamente ligada à formação de um tipo de pensamento que possibilita aos sujeitos, ao pensarem sobre os fenômenos do mundo no qual vivem, serem capazes de dar uma explicação que põe em relação dinâmica e histórica o seu próprio ser como sujeito que realiza a sua vontade consciente por meio dos fenômenos que estuda. Por isso, a sua atividade de expressão da autonomia se torna consciente e livre.

\section{0 valor da autonomia para autotransformação criativa pelos sujeitos}

A necessidade de produção de meios para que os estudantes se apropriem da forma de pensamento mais avançada já alcançada no desenvolvimento histórico da humanidade é uma constante na prática educativa em geral e na pedagógica escolar especificamente. É preocupação da didática, da organização e gestão da escolarização em todos os níveis de ensino. No entanto, essa apropriação não se efetiva sem a presença da personalidade, ou sem que o próprio pensamento tenha um valor vital para os indivíduos.

Neste tópico pretendo explicitar, então, por que a autonomia para pensar teoricamente, como na atividade de estudo, é importante para o desenvolvimento da personalidade do estudante. Mas, também, por que a personalidade do estudante precisa ser objetivo da mesma atividade na qual o pensamento se desenvolve. Essas afirmações decorrem, aqui, principalmente da explicitação feita por Davidov (1988, 
p. 178, grifo nosso) de qual é, a meu ver, a relação essencial entre a atividade de estudo e o conhecimento que é seu conteúdo, quando afirma que,

Os motivos das ações de estudo impulsionam aos escolares a assimilar os procedimentos de reprodução dos conhecimentos teóricos. Durante o cumprimento das ações de estudo os escolares dominam, antes de tudo, os procedimentos de reprodução de uns ou outros conceitos, imagens, valores e normas concretas e, por meio destes procedimentos, assimilam o conteúdo destes conhecimentos teóricos.

É importante notar aqui duas questões. A primeira é que, na realização da tarefa de estudo, o domínio dos procedimentos é condição fundamental para o domínio do conteúdo dos conhecimentos teóricos como processo de pensamento. Posto assim, fica claro que o estudante não está objetivando reproduzir o conhecimento dado, mas dominar um certo processo de pensamento relacionado às propriedades particulares do dado conhecimento por meio do procedimento geral do conhecimento teórico.

A segunda é que dominar os procedimentos é constituir a autonomia para pensar por meio deles na forma de uma lei do pensamento teórico. Ao dominar, dessa forma, os procedimentos da forma geral do pensamento teórico, o estudante reproduz em si e para si a consciência social da forma mais elaborada de pensamento alcançado historicamente pela humanidade. A liberdade para pensar com autonomia se constitui, então, como produto fundamental da atividade de estudo, que não é a aquisição de conhecimentos particulares, mas a capacidade de pensar sobre os conhecimentos de uma forma especial que permite ao estudante ser crítico do conhecimento proposto a ele pelo sistema escolar, por exemplo. Quais seriam, então as implicações para a formação da personalidade do estudante, poder agir com e sobre os conhecimentos?

A assimilação e o domínio dos procedimentos do pensamento estão ligados diretamente à motivação que liga o estudante à sua atividade, à sua participação como sujeito que alcançou autonomia para a realização das tarefas de estudo. A importância disso para a personalidade do estudante é 
que, como sujeito autor de uma dada ação, ele se vê no produto das transformações do material que ele mesmo realiza.

Esse ver-se no produto da sua atividade ocorre pelo processo de reflexão das próprias ações e operações. O estudante realiza ações fundamentais de controle e avaliação comparando os procedimentos com os resultados, estes com os objetivos da tarefa particular e com o objetivo geral da atividade. De acordo com Davidov (1988, p.184),

As ações de estudo de controle e avaliação têm um grande papel na assimilação dos conhecimentos pelos escolares. O controle consiste em determinar a correspondência de outras ações de estudo às condições e exigências da tarefa de estudo. [...]

A ação de avaliação permite determinar se está assimilado (e em que medida) ou não o procedimento geral de solução da tarefa de estudo dada, se o resultado das ações de estudo corresponde (e em que medida) ou não a seu objetivo final, [...]

A essencialidade, a meu ver, do controle e da avaliação como ações de estudo é o estabelecimento de um valor para os resultados da ação. Isto é, as operações que realizam a tarefa de estudo causam transformações no seu objeto/conteúdo que precisam estar coerentes com o resultado final objetivado pela tarefa posta pelo indivíduo como realização da sua vontade consciente. $\mathrm{O}$ acerto ou erro nos procedimentos afeta pessoalmente o estudante de modo que ele pode se ver na própria avaliação, mas também, na avaliação que os outros colegas e professores fazem da sua atividade. Então, o domínio correto dos procedimentos do pensamento tem essencial papel na formação da personalidade do estudante quando este reflete sobre o seu lugar na comunidade de estudantes, na escola, diante do conhecimento e dos professores.

Sabemos que o lugar que o estudante ocupa nas relações sociais é muito importante para a sua participação no grupo, adesão às atividades, criação de interesse e motivos pessoais para estudar. Reconhecer-se e ser reconhecido como um membro que participa positivamente nas atividades do grupo eleva o valor pessoal e, ao mesmo tempo, o valor da atividade que realiza como sujeito social. 
Por isso, entendo que Davidov (1988) atribui à reflexão o fundamental papel no desenvolvimento psicológico dos estudantes, afirmando que,

Tomando consciência da significação social que tem a participação no cumprimento destes tipos de atividade, os adolescentes entram em novas relações mútuas, porquanto estas atividades se realizam coletivamente e seus resultados recebem uma verdadeira valoração na coletividade (seja escolar, laboral, desportiva ou qualquer outra). (p.84, grifo nosso).

Semelhante exame, pelos escolares, dos fundamentos das ações próprias, chamado reflexão, conforma a condição essencial para que estas ações se estruturem e mudem corretamente. A atividade de estudo e alguns de seus componentes (em particular, o controle e a avaliação) se realizam graças a uma qualidade tão fundamental da consciência humana como é a reflexão. (p. 184, grifo nosso).

A atividade de estudo organizada corretamente, como propõem V.V. Davidov (1988; 1999), Davydov (1981; 1990; 1992), D.B. Elkkonin (1999) e V. V. Repkin (2003), propõe-se a dirigir os estudantes não somente para os conhecimentos, ou mesmo, à sua essencialidade, o domínio dos procedimentos do conhecimento teórico. Ainda, e significativamente importante é a formação da personalidade, pelo desenvolvimento harmonioso e enriquecido da cultura elaborada historicamente na constituição do sistema psicológico e da consciência da pessoa, isto é, a unidade psicológica do indivíduo como sujeito que resulta em personalidade.

Podemos avaliar essa importante questão, negligenciada em nossas escolas atualmente, pelas seguintes considerações:

Simultaneamente a experiência da atividade criadora não deve ser, a nosso ver, um dos quatro elementos equivalentes da experiência social integral, senão o elemento fundador e principal no qual podem apoiar-se os outros (ou seja, os conhecimentos, as capacidades e as relações do indivíduo para com o mundo). Neste caso, o ensino e a educação das crianças desde o começo mesmo estarão dirigidos ao desenvolvimento de sua personalidade. (DAVIDOV, 1988 p. 170, tradução e grifo nossos).

A necessidade de um estudo especial da atividade de estudo tornase ainda mais clara à luz do trabalho sobre o problema do cultivo da personalidade dos escolares de menor idade. (ELKONIN, 1999 p. 86, tradução e grifo nossos).

Por conseguinte, é necessário orientar o ensino não diretamente para a formação de alguns conhecimentos, habilidade e hábitos, 
senão para a explicação para as crianças do sentido pessoal do próprio estudo, para o desenvolvimento da atitude adequada das crianças diante do estudo e sua motivação, e para a formação da personalidade em geral. (LOMPSCHER; MARKOVA; DAVIDOV, 1987, p. 11, tradução e grifo nossos).

Uma situação de aprendizagem (SA) surge em uma personalidade desenvolvida com uma hierarquia definida de valores, na qual, longe de ser a última coisa, é ocupada por autoconsciência, autoavaliação como agente (o auto-valor "eu"). (REPKIN, 2003 p. 28 , tradução e grifo nossos).

Para analisar por que a personalidade é o elemento fundador e principal no qual se apoiam os conhecimentos, as capacidades e as relações dos indivíduos é preciso considerar que ela é a expressão da máxima complexidade do indivíduo singular na sua relação com o gênero humano. Que a educação esteja dirigida à sua formação implica analisar sob quais particularidades genéricas sociais se formam essa personalidade do estudante na escola, posto que o gênero humano é a totalidade da autocriação da humanidade por meio do desenvolvimento histórico da sociedade, e, ao mesmo tempo, a personalidade representa a autocriação do indivíduo singular por si mesmo em contradição com as particularidades das unidades sociais das quais participa, como a escola, por exemplo.

A atividade de estudo é uma particularidade singular da escola da qual o estudante participa. Por isso, cada escola, por meio da atividade de estudo que organiza e inclui o estudante, cultiva a sua personalidade. Isto quer dizer que observa e prepara, no conjunto da atividade, quais serão as mediações particulares necessárias ao desenvolvimento da personalidade do estudante, de modo que este possa exercer a sua autotransformação no movimento singular das transformações da própria atividade de estudo particularizada por aquela escola.

É nessa medida que a atividade de estudo mediada por determinadas particularidades previstas pelo professor pode, no ensino do uso dos meios e instrumentos de realização operacional das tarefas de estudo, viabilizar a formação de sentido pessoal para os estudantes. Isto é, o desenvolvimento de uma atitude adequada e motivação para a atividade de estudo na qual podem ser agentes de tal autotransformação apontada acima. 
Nesse movimento contraditório entre o estudante singular e as mediações particulares postas pela atividade de estudo, aquele consegue organizar e estabelecer uma hierarquia de valores e motivos a estas, que irão constituir a sua autoconsciência de estudante. Transcorrendo assim, o estudante adquire todas as condições para efetivar processos de avaliação da atividade de estudo como atividade sua. Por isso, ao final, é possível para ele estabelecer não somente um auto valor para si como pessoa, mas, inclusive, um valor objetivo e socialmente referenciado para o estudar como possibilidade de efetivação de si como sujeito social.

Uma característica importante da formação da personalidade, portanto, é que, no seu núcleo, como sistema "EU”, opera-se um processo de autocriação, autotransformação do ser para si e para os outros. Essa criação tem como fonte a transformação que o sujeito opera na realidade objetiva junto com pares em processo de colaboração, de atuação em uma mesma atividade. O mesmo para a atividade de estudo compreendida aqui como realizada socialmente e não de forma isolada. Na perspectiva de Elkonin (1961, p. 240 apud PUENTES, 2018, p.772) "[...] a autotransformação da própria criança como produto (é o objeto da atividade de estudo), a partir das transformações que se operam durante a execução no objeto [...]”. Ainda, Repkin (2003, p. 15) aponta para a centralidade da formação da personalidade, quando afirma que,

Uma pessoa se desenvolve como personalidade apenas na medida em que ela se desenvolve como um agente ${ }^{2}$, pois a atividade de uma pessoa nunca é atividade individual. Qualquer atividade que está conectada com outras pessoas ou envolve outras pessoas é de uma forma ou de outra conjunta, atividade social. Esta é a forma na qual uma pessoa inicia contato com outras pessoas e interage com elas - isto é, se transforma como uma personalidade.

A apropriação, como forma de autotransformação criativa dos modos de ser da personalidade, a ponto de que os indivíduos não somente se apropriem da cultura mais elaborada, mas que possam efetiva e criticamente promover a transformação da sua sociedade, precisa ser o horizonte para o desenvolvimento do pensamento

\footnotetext{
2 Um agente é uma fonte de dinamismo, uma fonte de atividade. A atividade é o modo de existência do agente, e ele não existe em qualquer outra forma que não seja a atividade. Assim, um agente é uma forma estabelecida de existência de atividade, de atividade potencial (REPKIN 2003, p. 16).
} 
teórico. Uma questão fundamental para o desenvolvimento humano é que a sociedade possa educar seus sujeitos para que tenham a própria humanidade como escopo da sua atividade social. A superação do individualismo em direção a uma existência comunitária é uma exigência de valor vital para a humanidade, que pode efetivamente ser alcançado quando a atividade de estudo, na perspectiva proposta por estes autores, promove o desenvolvimento autônomo e crítico da consciência dos estudantes sem que eles percam a comunidade de onde surge a sua própria atividade. Autonomia e comunidade são complementares.

A importância da escola como o espaço historicamente desenvolvido no qual e pelo qual, considerando a sua atividade, as crianças têm a possibilidade de se apropriar dessa forma de pensamento a coloca em uma posição de relevo na sociedade e para a formação cultural. É importante considerar, por isso, que na escola, por meio da correta organização da atividade de estudo, as crianças podem desenvolver não somente processos cognitivos a partir dos conteúdos e materiais de estudo relacionados à ciência, arte, filosofia, política, economia, mas, principalmente, relações sociais pelas quais compreendam o valor da vida comunitária e o correspondente desenvolvimento da sua personalidade para um novo tipo de sociedade a ser produzida por elas mesmas no futuro. Nas palavras de Elkonin,

O desenvolvimento do pensamento teórico é possível somente onde um problema teórico emerge, mas ele pode emergir somente em um mundo ampliado. O principal objetivo deve ser expandir o mundo da criança em profundidade e amplitude além das fronteiras do seu mundo diretamente perceptível. (EL'KONIN, apud HAKKARAINEN; VERESOV, 1999, p. 5-6, grifo no original).

O alargamento do mundo da criança, nesse sentido, não se dá apenas em propiciar o contato com o maior número possível de objetos da cultura, mas que, nesse oferecimento, seja igualmente possível a própria criança aprofundar o conhecimento sobre tais objetos pelo pensamento teórico transformador do conhecimento sobre os objetos e sobre si mesmo nessa relação. O valor da autotransformação criativa pela atividade de estudo, nesse sentido, liga-se ao fato de que o domínio dos procedimentos do pensamento teórico pode agir em duas linhas diferentes, complementares e necessariamente coexistentes. Essa 
autotransformação da personalidade que ocorre pela transformação ativa, criadora e objetivada pelo estudante sobre a realidade concreta, pode, por isso, ser revolucionária tanto para a personalidade quanto para as ações que a partir dela o indivíduo estabelece em relação à sua sociedade. Só uma personalidade que tem domínio consciente sobre si mesma, autonomia, pode realizar tal transformação.

\section{Pensamento teórico, personalidade e prática revolucionária}

Na atividade revolucionária, o transformar a si mesmo coincide com o transformar as circunstâncias (MARX, 2007, p. 209).

Começaremos este tópico por uma citação de Vygotski (2000), para analisar a questão principal deste artigo sobre por que é importante iniciar a atividade de estudo pelo pensamento teórico. O autor apresenta a seguinte proposição:

A consciência científica [...] considera que a revolução e a evolução são formas de desenvolvimento vinculadas entre si, formas que se pressupõem reciprocamente. Para a consciência científica o próprio salto que se produz durante estas mudanças no desenvolvimento da criança é um ponto determinado em toda a linha do desenvolvimento. (p. 141-142).

[...] A própria essência do desenvolvimento cultural radica na colisão dos desenvolvimentos das formas culturais da conduta, que a criança vai conhecendo, com as formas primitivas que caracterizam seu próprio comportamento. (p. 142, grifo nosso).

Para responder à questão posta desde o início do artigo, precisamos considerar, agora, essa afirmação sobre o fato de o desenvolvimento ser revolucionário, e que a essência deste processo é a colisão entre sistemas diferentes, o natural e o cultural. Nessa questão radica a essencialidade, também, do porquê da diferença entre o pensamento teórico e o pensamento empírico, que não supera os processos de percepção, fundada nos meios primitivos da sensibilidade.

Partimos, então, da compreensão do surgimento do pensamento como uma necessidade gestada no processo de desenvolvimento histórico dos homens entre si e com a natureza. Estamos nos baseando no fato de que, em sociedade, os 
processos primitivos da sensibilidade e da percepção entram em colisão com as novas necessidades de conhecimento criadas pela prática social de produção da vida. Pensar, então, tornou-se um problema vital.

Sendo, assim, um problema vital social, o pensamento não poderia ser concebido como um fenômeno de natureza individual. Por isso, a primeira providência para analisar o surgimento do pensamento e o seu desenvolvimento histórico nos indivíduos é tomar novamente aquelas condições do surgimento da atividade vital consciente: a transformação social da natureza, a comunicação intercâmbio - e a linguagem ou significação.

Essa conversão do sujeito em sujeito do pensamento é um processo revolucionário, porque é um salto qualitativo a ruptura do uso preponderante dos processos perceptivos para a análise da realidade objetiva. Significa a superação, por incorporação, do sistema primitivo por meio de um sistema criado pela atividade humana: o sistema de significação e sua transformação em linguagem. Como explica Vygotski (2000, 84, grifo do autor), “[...] a atividade mais geral e fundamental do ser humano, a que diferencia em primeiro lugar o homem dos animais, do ponto de vista psicológico é a significação, isto é, a criação e o emprego dos signos [...], isto é, de sinais artificiais."

A criação desse sistema se dá na atividade transformadora da realidade. Por isso, a significação na atividade de estudo acontece por meio do processo de transformação do seu objeto. Assim, quando Davidov (1988, p. 182, grifo nosso) expõe as principais peculiaridades das ações de estudo, salienta que,

A ação inicial (podemos dizer principal) é a transformação dos dados da tarefa de estudo com a finalidade de revelar certa relação universal do objeto dado, o que deve ser refletido no correspondente conceito teórico. É importante assinalar que se trata da transformação orientada a um fim dos dados da tarefa, dirigida a buscar, descobrir e distinguir uma relação completamente definida de certo objeto integral.

Quero ressaltar que a função do pensamento no sistema psicológico é essencialmente a de análise, abstração e sintese (RUBINSTEIN, 1959) da diversidade da existência objetiva e subjetiva. Um processo de afastar, ou desagregar e agrupar 
por conexões, ligações, coerência, etc. de modo a criar idealmente gêneros dinâmicos de inter-relações que permitam abarcar a complexidade da realidade em suas múltiplas formas e conteúdos na formação de conceitos.

A generalização como processo de organização do mundo se apresenta em diferentes tipos que foram estudados por L. S. Vygotski (2001; 1996); A. R. Leontiev (1978); V. V. Davydov (1981) e que caracterizam tanto o processo evolutivo quanto o revolucionário do desenvolvimento do pensamento.

Podemos pensar, então, que cada momento no desenvolvimento do pensamento representa uma transição evolutiva e revolucionária do pensamento que caminha no sentido da apropriação das formas mais complexas de análise da realidade socioculturalmente desenvolvidas que dependem tanto das condições naturais, básicas das funções psíquicas, quanto da atividade social na qual o sujeito está inserido. Aqui, é importante ressaltar, mais uma vez, que a atividade é essencial para essas transições, tanto a motora quanto a de significação.

$\mathrm{Na}$ exposição didática e resumida das proposições de L. S. Vigotski proferidas por Davydov (1992, p. 2-3), notamos que as distintas formas "amontoados sincréticos [...], objetos reagrupados sem um fundamento suficiente, segundo uma impressão casual”; o "complexo - a criança junta os objetos apenas segundo a experiência sensível imediata, ainda conforme nexos objetivos”, e "o pseudo-conceito - a unificação foi efetuada pela criança segundo um genuíno reconhecimento visual [...] que conserva, também, o nosso pensamento cotidiano, que se baseia na linguagem comum" -, passam pela transição da forma primitiva da sensibilidade ao uso das palavras, dos signos e dos significados pelo mesmo princípio da sensibilidade socialmente constituída. Restou, então, o problema apontado por Davydov (1992) da análise da transição do pseudo-conceito ao conceito científico. Em suas palavras e segundo o próprio L.S. Vigotski, "A solução consiste em mudar o ponto de vista pelo qual se considera o conceito mesmo, ao passar para uma análise de sua dialeticidade" (DAVYDOV, 1992, p. 4).

O principal problema aparece no fato de que ocorre uma persistência na vida do adulto na forma de pensamento com base nos pseudo-conceitos, isto é, um adulto pode não superar essa forma de pensamento pelo fato de que a sua 
atividade, cotidiana, não oferece situações nem meios para tal superação e transição à forma conceitual científica mais desenvolvida. Se retomarmos as condições do desenvolvimento psicológico e considerarmos que a atividade é fundamento para tais transformações, fica compreendido esse problema do desenvolvimento do pensamento na sua forma mais desenvolvida. Nas palavras de Vigotski (apud DAVYDOV 1992, p. 4),

Mas os mesmos conceitos do adolescente e do adulto, na medida em que sua utilização se limita à esfera da simples experiência cotidiana, frequentemente não superam o nível dos pseudoconceitos e, também tendo todas as características do conceito do ponto de vista lógico-formal, não o são, ainda, características do conceito do ponto de vista da lógica dialética, ficando não mais que representações comuns, isto é, complexos.

$\mathrm{Na}$ análise da formação dos conceitos espontâneos e dos científicos, Vigotski (2001) demonstra que os espontâneos se desenvolvem por meio do uso da palavra para incluir os objetos e relações concretas em determinadas classes formando uma representação geral - do objeto para o conceito - com base no uso cotidiano da linguagem. Essa atividade do pensamento com base no uso do signo como meio da sua relação concreta, por meio da qual toma consciência das relações aparentes das coisas não expressa a essencialidade delas, isto é, as suas relações e conexões internas. Essa forma do pensamento é ainda, portanto, pseudo-conceito.

O desenvolvimento do conceito propriamente dito, do conceito científico, começa, de acordo com Davydov (1992, p. 5, grifo nosso), “[...] com o trabalho sobre o conceito mesmo enquanto tal, da sua designação verbal, daquelas operações que não pressupõem um uso espontâneo destes conceitos”. A via do desenvolvimento deste tipo de conceito não é a relação imediata com os objetos concretos da sua atividade, mas essa mesma relação mediada pelas relações lógicas entre objetos em direção ao objeto concreto, por isso realiza o caminho do conceito para o objeto e não o contrário. As consequências para a formação da consciência são compreendidas a partir do fato de que

A consciência das operações do pensamento significa a sua reprodução, o seu radicar-se na imaginação e a sua expressão 
verbal. Isto está imprescindivelmente conectado com a generalização dos próprios pensamentos e com o dirigir-se da consciência ao plano da própria atividade pessoal, isto é, com a reflexão. Isso produz aquele tipo particular de generalização que existe no conceito científico e implica as formas superiores do pensamento humano. (DAVYDOV, 1992, p. 5, grifo nosso).

Temos, por isso, que o trabalho que vai do conceito ao objeto exige o emprego de funções do pensamento, como análise, abstração e síntese que levam ao desenvolvimento de outras funções essenciais para a formação da própria personalidade, como a reflexão, uma nova hierarquia de valores, o lugar e a participação do sujeito, por exemplo. Iniciar por esse tipo de atividade de pensamento reestrutura todo o sistema de funções psicológicas que estarão subordinadas a uma nova forma de organização da atividade. A orientação da atividade por um tipo diferente de tarefa a ser realizada modifica os meios e instrumentos, o seu uso e finalidade e a transição do plano de ação da atividade motora para o pensamento.

Nesse sentido, altera-se a relação vital do sujeito com a atividade, sua motivação, sentidos e necessidades. A relação vital do indivíduo social não é uma relação mecânica de sobrevivência, visto que uma característica essencial da atividade humana é a criação, a transformação da natureza por meio da conexa autotransformação de si, do valor vital que tem para ele esse movimento de criação e autocriação do ser em dadas circunstâncias modificadas por ele. Nesse movimento, como propõe Repkin (2003, p. 16, tradução nossa), "Tornar-se uma personalidade é uma tarefa vital. Enquanto uma pessoa torna-se um agente espontaneamente, ele somente pode vir a ser uma personalidade conscientemente, na medida em que dá uma direção à sua vida”. Por isso, na atividade em que o sujeito pode vir a ser uma personalidade consciente, ele alcança também autonomia, a possibilidade de pôr para si objetivos em relação à sua atividade por meio da reflexão, compreendida como "a avaliação dos resultados do pensamento anterior" (REPKIN, 2003, p. 27, tradução nossa), isto é, como o meio pelo qual o sujeito avalia o seu próprio ser agente em dada atividade e referente a determinadas tarefas que estão presentes em sua vida e que têm para ele um sentido vital. 
Davidov (1988) enfatiza que a atividade de estudo somente acontece quando o sujeito é portador de uma necessidade para isso. É claro para nós que a necessidade do sujeito é igualmente uma necessidade da pessoa, do ser integral, da totalidade social que representa o indivíduo. Por isso, a atividade de estudo precisa ser, antes de tudo, uma atividade da pessoa dirigida à sua autotransformação.

Nesse sentido, o sujeito da atividade de estudo, quando inicia pelo pensamento teórico, é forçado pelas circunstâncias a alterar a sua relação com a realidade, superar os meios cotidianos da percepção sensível e alçar uma forma totalmente diferente daquela pela qual realiza o seu ser no mundo. Marx (2007, p. 534), quanto a isso, afirma que "A coincidência entre a altera[ção] das circunstâncias e a atividade ou automodificação humanas só pode ser apreendida e racionalmente entendida como prática revolucionária”. Por isso, quero colocar aqui um termo de igualdade entre a autotransformação, a prática revolucionária e o pensamento teórico. O pensamento teórico representa, então, uma verdadeira revolução para a personalidade. O nível de reflexão alcançado pelo pensamento teórico devolve a personalidade alienada do sujeito pelo pensamento empírico ao seu verdadeiro dono, o indivíduo consciente do seu ser social.

A atividade de estudo, pensada desta maneira, como propõem os autores referenciados, é, por isso, ela mesma, uma necessidade social vital. Porque revolucionária no plano da personalidade dos indivíduos, quiçá, possa ser igualmente revolucionária por meio de uma nova geração de estudantes, para a própria sociedade.

\section{Considerações finais}

A discussão sobre o desenvolvimento do pensamento teórico na atividade dos estudantes é uma questão de fundamental importância na atualidade. Porque é muito evidente que os nossos estudantes, mas também, em larga medida e por consequência da formação onde não se encontrou essa proposta, os professores não dominam os procedimentos dessa forma de pensamento. Trata-se, então, de destacar a atividade de estudo, como é proposta pelos autores aqui representados, como uma necessidade premente para a formação de professores e estudantes. 
Aponto para essa necessidade, visto que, sem a devida formação de professores para a correta organização da atividade de estudo, nossos estudantes podem, por muito tempo ainda, não superar aquilo que L. S. Vigotski apontou como fenômeno social do processo educativo no qual e pelo qual isso seria possível aos estudantes mais novos e aos adolescentes: a persistência do pensamento com base no pseudo-conceito, do pensamento que não supera a necessidade da atividade cotidiana. Por isso, o estado de alienação e a formação de uma personalidade contrária à atividade de estudo têm se constituído de forma geral.

Os resultados dessa contradição aparecem de forma muito clara no ambiente escolar, no sofrimento psicológico tanto dos professores quanto dos alunos. Para os pequenos, em sua maioria, a atividade de estudar é uma obrigação realizada a contragosto; da mesma forma, é a atividade de ensinar para a maioria dos professores, quando repetidamente se frustram com o resultado da sua atividade.

É mais contraditório ainda quando os alunos e professores festejam pelo fato de que não terão aula por algum motivo. Tomando a criatividade como essencialidade da atividade humanizadora, na transformação da realidade que se constitui como meio para atividade vital e na superação das contradições postas pelo gênero social, percebemos, então, que, nas nossas escolas, esse processo humanizador não se realiza a contento. Estudar não se constitui como o sentido pessoal de autotransformação da personalidade.

É importante considerar, nesse sentido, e para as finalidades deste artigo, algumas qualidades do pensamento teórico e suas implicações para a formação da personalidade dos estudantes. Uma vez que a colisão de sistemas radica na própria atividade transformada, a partir da contradição entre a atividade natural e a cultural, e que é por meio da atividade nos seus diferentes processos culturais que se caracterizam os períodos de transição do desenvolvimento e da personalidade, entendemos que a atividade organizada desde o início pelo pensamento teórico, como no caso da atividade de estudo, representa a possibilidade do salto qualitativo no pensamento que supera o pensamento empírico e abre a possibilidade de pensar a realidade em um nível superior de análise. 
A primeira característica do pensamento nesse plano, que é importante notar, é que ele só se formará em u ma atividade especialmente planejada para isso e sob a mediação de professores que organizam esta atividade para esse fim específico (DAVIDOV, 1999). A segunda, ocorre por um processo de imaginação criativa na formação de um sistema conceitual que possibilita pôr à prova o conteúdo da realidade representado nos conceitos sem a necessidade da relação direta com os objetos desse conteúdo (DAVYDOV, 1990). Essa atividade altera a organização discursiva, lógica, do pensamento de modo que a generalização, por meio da análise, a abstração e a síntese da atividade, é agora uma ação que se realiza no pensamento (LEONTIEV, 2005). E a terceira característica refere-se ao domínio do movimento concreto da gênese e desenvolvimento, contradições e transições, da realidade concreta pelo pensamento (DAVYDOV, 1990), que possibilita o sujeito agir, ser agente das possíveis transformações na realidade por meio do experimento concreto e mental, do vir a ser, da utilização prática na transformação da realidade.

Quero destacar, ainda, algumas ideias entre a relação ensino/aprendizagem, formação da personalidade e pensamento teórico. Quero notar que a personalidade é resultante da atividade social, mas que, também, tem implicações para a própria atividade social dos indivíduos. Nesse sentido, a atividade social é também formada pela personalidade humana, isto é, as relações sociais adquirem as qualidades das personalidades que cria. Assim, o conjunto das relações sociais particulares de um indivíduo são caracterizadas também, por ele mesmo, como diria Vygotski (2000), como drama, como luta, como colisão de sistemas, quando ele mesmo se apresenta como um sistema pessoal frente ao sistema social. Ou, como diria Marx (2007, p. 43), "[...] as circunstâncias fazem os homens assim como os homens fazem as circunstâncias".

Quais são as implicações para a personalidade do estudante? Primeiro, os conhecimentos teóricos só poderão ser dominados pelo estudante quando ele mesmo domina os procedimentos dessa forma de pensamento, quando participa da atividade escolar que o coloca frente a esse tipo de conhecimento e trava uma verdadeira luta entre o pensamento espontâneo e o teórico, o 
conceito científico. Se a atividade de estudo se resume à utilização do pensamento empírico, formal, cria-se um sistema lógico de reprodução verbal, discursiva do conhecimento que evidentemente não o habilita a operar no pensamento nem tampouco na realidade com os conceitos teóricos.

Os conhecimentos, nesse caso, não servirão para uma análise complexa da realidade. Não serão meios para a resolução de problemas não cotidianos, isto é, problemas da ciência, da arte, da filosofia, da política etc. que constituem o mundo mais amplo de que ele precisa se apropriar para a sua plena humanização.

Segundo, e por isso mesmo, não se desenvolverão no pensamento aquelas funções do processo de imaginação criativa que possibilita o experimento mental, o planejamento de ações novas na realidade, a criação de meios e instrumentos, de novos conceitos que permitem criar hipóteses de soluções para os problemas da sua própria, e da sua comunidade, atividade vital. Podemos pensar no drama, na colisão dos desejos próprios com as determinações de uma realidade não compreendida, que enfrentam os sujeitos que, na impossibilidade de pensarem por si próprios os destinos da vida, dependem que outras pessoas que façam para eles as escolhas que deveriam ser genuinamente suas.

Terceiro, que, em consonância com o que foi dito acima, não se forma no pensamento do sujeito um sistema explicativo dos fenômenos, característica essencial do pensamento teórico, que lhe possibilita antecipar-se ao vir a ser da realidade na qual existe, planejar com consciência as transformações necessárias, ter autonomia para criar e recriar as condições de sua vida

É por isso que uma educação que se preocupa com a formação da personalidade, que considera o drama do desenvolvimento e do sentido vital do pensamento para o enfrentamento desse drama prepara o estudante não somente para ter meios de enfrentamento da realidade contraditória, mas, na mesma medida em que o pensamento teórico é revolucionário, habilita as novas gerações para essa tarefa revolucionária da transformação da sociedade, do sentido vital da existência humana criada por elas mesmas. 


\section{Referências}

DAVIDOV, V. La enseñanza escolar y el desarrollo psíquico: Investigación psicológica teórica y experimental. Tradución de Marta Shuare. Moscú: Progreso, 1988.

DAVIDOV, V. O que é a atividade de estudo. Tradução de Ermelinda Prestes. Escola inicial, n.7, p.1-9, 1999.

DAVÝDOV, V. Tipos de generalización en la enseñanza. La Habana: Pueblo y Educación, 1981.

DAVYDOV, V. Types of Generalization in Instruction: Logical and Psychological Problems in the Structuring of School Curricula. Translated by Joan Teller. Soviet Studies in Mathematics Education. Volume 2. Reston, Virginia: National Council of Teachers of Mathematics, 1990.

DAVYDOV, V. O problema da generalização e do conceito na teoria de Vygotsky. Texto de conferência proferida na reunião do Comitê Internacional da International Society for Cultural Research and Activity Theory. Departamento de Ciências Psiquiátricas e Medicina Psicológica da Universidade de Roma, 1992.

EL'KONIN, D. B. On the Structure of Learning Activity. Journal of Russian \& East European Psychology, 1999. 37:6, 84-92.

LEONTIEV, A. N. Actividad, conciencia y personalidad. Buenos Aires: Ediciones del Hombre, 1978.

LEONTIEV, A. N. Lecture 37. The Genesis of Human Thinking. Journal of Russian and East European Psychology, vol. 43, no. 5, September-October 2005, p. 53-64. DOI: https://doi.org/10.1080/10610405.2005.11059260.

LOMPSCHER, J.; MARKOVA, A.K.; DAVIDOV, V. V. Formación de la actividad docente de los escolares. Editorial Pueblo y Educación: La Habana, 1987.

MARX, K.; ENGELS, F. Manuscritos econômico-filosóficos. Tradução de Jesus Raniere, São Paulo: Boitempo Editorial, 2004.

MARX, K.; ENGELS, F. A ideologia alemã. Tradução de Rubens Enderle; Nélio Schneider; Luciano Cavini Martorano. São Paulo: Boitempo, 2007.

HAKKARAINEN, P.; VERESOV, N. Editors' Introduction: D.B. El'konin and the Evolution of Developmental Psychology. Journal of Russian \& East European Psychology, 1999. 37:6, 3-10. DOI: https://doi.org/10.2753/rpo1061-040537063.

PUENTES, V. R.; CARDOSO, C. G. C.; AMORIN, P. A. P. A atividade de estudo segundo V. V. Repkin: uma abordagem crítica na perspectiva da Teoria da Subjetividade. Ensino em Re-Vista | Uberlândia, MG, v.25, n.3, p. 766-789, set./dez. 2018. ISSN: 1983-1730. DOI: https://doi.org/10.14393/ER-v25n3a2018-13. 
REPKIN, V. V. Developmental Teaching and Learning Activity. Journal of Russian and East European Psychology. vol. 41. no 5, September-October 2003, p. 10-33.

RUBINSTEIN, S. L. El pensamiento y los caminos de su investigación.

Montevideo: Ediciones Pueblos Unidos, 1959.

VIGOTSKI, L. S. A construção do pensamento e da linguagem. 1. ed. São Paulo: Martins Fontes, 2001.

VYGOTSKI, L. S. Obras escogidas. Tomo IV: Psicología infantil. Traducción de Lidia Kuper. Madrid: Visor, 1996.

VYGOTSKI, L. S. Obras escogidas. Tomo I. 2 ed. Traducción de José Maria Bravo. Madrid, Visor, 1997.

VYGOTSKI, L. S. Obras escogidas. Tomo III: Problemas del desarrollo de la psique. Traducción de Lidia Kuper. Madrid: Visor, 2000.

VYGOTSKI, L. S. Obras escogidas. Tomo II: Problemas de psicología general. 2 ed. Traducción de José Maria Bravo. Madrid: Visor, 2001. 